Utah State University

DigitalCommons@USU

Green Canyon Environmental Research Area, Logan Utah

Quinney Natural Resources Research Library,

S.J. and Jessie E.

1983

\title{
The Effects of Ultraviolet-B Radiation on Plant Competition in Terrestrial Ecosystems
}

Warren G. Gold

Martyn M. Caldwell

Follow this and additional works at: https://digitalcommons.usu.edu/grcanyon

Part of the Ecology and Evolutionary Biology Commons, Plant Sciences Commons, and the Soil Science Commons

\section{Recommended Citation}

Gold, W. and Caldwell, M. (1983). Effects of ultraviolet-B radiation on plant competition in terrestrial ecosystems. Physiologia Plantarum, 58(3): 435-444.

This Article is brought to you for free and open access by the Quinney Natural Resources Research Library, S.J. and Jessie E. at DigitalCommons@USU. It has been accepted for inclusion in Green Canyon Environmental Research Area, Logan Utah by an authorized administrator of DigitalCommons@USU. For more information, please contact digitalcommons@usu.edu.

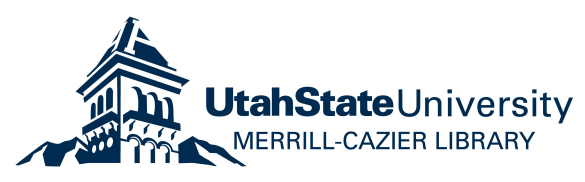




\title{
The effects of ultraviolet- $B$ radiation on plant competition in terrestrial ecosystems
}

\author{
Warren G. Gold and Martyn M. Caldwell
}

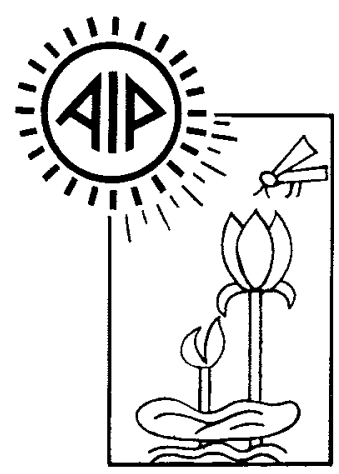

नूतं जना: सूर्येए प्रसूता Gold, W. G. and Caldwell, M. M. 1983. The effects of ultraviolet-B radiation on
plant competition in terrestrial ecosystems. - Physiol. Plant. 58: 435-444.

Evidence regarding the interaction of ultraviolet-B (UV-B, 280-320 nm) radiation and plant competition in terrestrial ecosystems is examined. The competitive interactions of some species pairs were affected even by ambient solar UV-B radiation (as exists without ozone depletion), when compared to control pairs grown without UV-B. Also, the total shoot biomass of these species pairs was depressed under ambient UV-B. Relatively large increases in UV-B radiation (approximating a $40 \%$ ozone layer reduction when weighted with the generalized plant action spectrum) altered the competitive interactions of some species pairs grown in pots under field conditions, but did not affect the total shoot biomass production of those pairs. Recent field experiments have examined the competitive interactions of wheat (Triticum aestivum L. cv. Bannock) and wild oat (Avena fatua L.) under a simulated increased UV-B regime resulting from a $16 \%$ ozone layer reduction when weighted with the generalized plant action spectrum. This increase in UV-B altered the competitive interactions of these two species without affecting the total shoot biomass production of the species pair. The manner in which increased UV-B affected the relative competitive abilities of the two species was highly dependent upon the environmental conditions during the early life stages of the plants. The implications of these results for both agricultural and natural plant communities are discussed.

Additional key words - Ozone reduction, plant interference.

W. G. Gold (reprint requests) and M. M. Caldwell, Dept. of Range Science and the Ecology Center, Utah State Univ., Logan, Utah 84322, USA.

This paper is part of the contribution to the International Workshop on the Effects of Ultraviolet Radiation on Plants, held in Delhi, India, 1-5 November, 1982.

\section{Introduction}

Environmental stresses often impose constraints upon the vegetative and/or reproductive production of higher plants. These stresses can be either physicochemical (e.g. temperature, moisture, radiation) or biotic (e.g. parasitism, competition) in nature (Levitt 1980). The stresses can act directly (e.g. by affecting the actual photosynthetic carbon gain ability of the plant) or indirectly (e.g. through an increase in energetic demands to facilitate survival in a stressful environment). In addition, plants under natural conditions are usually subject to many different types of stresses which often interact with each other. Thus, plants in the field are exposed to a complex of environmental stresses, which affect plant growth and survival, rather than a set of isolated stresses. The nature of this stress complex incident upon a plant may change through time since the relative importance of individual stresses and the interrelationships between stresses change within and between growing seasons (e.g. Björkman 1981).

Most studies of plant response to an environmental stress have either isolated plants from all other stresses present in the natural environment or held those other stresses constant. Although these studies allow an examination of the physiological response to a single stress, they have limited value in predicting the response to a change in that stress under natural conditions. In 
general, plants appear much less sensitive to increased UV-B radiation $(280-320 \mathrm{~nm})$ in the field (Caldwell 1981) than in the greenhouse, where a significant portion of the stress complex has been removed or altered. Numerous studies indicate that factor interaction is an important aspect of a plant's response to its environment. For example, Mueggler (1972) and Lee and Bazzaz (1980) have shown that plant response to defoliation is highly dependent upon the degree of competition present. Thus, the interpretation of a change in a single stress in an ecological context requires the consideration of other natural stresses, including biotic interactions.

Plant competition is a conflict for resources which necessarily has both spatial and temporal components. Competition occurs when two or more neighboring individuals attempt to acquire the same limited resource at the same time. All of the studies reviewed in this paper examined relative changes in shoot biomass, which suggest the existence of plant interference (Harper 1977). Although these results will be taken to indicate the presence of competition, the lack of evidence of a resource limitation leaves open the possibility of other forms of interference such as allelopathic interactions being responsible for the observed results. Plant competition is manifested upon an individual plant through an increase in physicochemical environmental stress, rather than having a direct effect per se. For example, the actual effect of competition for water by individual plants will be increased water stress, and perhaps nutrient stress. Since plants probably often compete for more than one limited resource over a short period of time, competition may induce complex changes in the entire set of stresses that act upon individual plants.

The resistance of a plant (Levitt 1980) to a change in the current set of environmental stresses is, in part, a genotypically controlled, species-specific characteristic. Thus, an alteration of any single environmental stress could lead to changes in the competitive situation of a plant community through the differential resistance of the competing species to that change. Bennett and Runeckles (1977) found a change in the competitive interaction of two species (Lolium multiflorum and Trifolium incarnatum) as a result of small changes in a stress (ozone concentration). This change in the competitive situation of certain species could further alter the productivity of those species beyond that of the direct physiological effects of a change in the stress itself (Grime 1977, 1979).

Ultraviolet radiation has been recognized as an environmental stress for over a century (Caldwell 1981). Caldwell et al. (1982) have suggested that UV-B radiation was a selective force in low latitude alpine environments, where the present UV-B sensitivity of the resident species is lower than their arctic counterparts (ecotypes or congeners). There is some evidence that ambient solar UV-B radiation as exists without ozone reduction can have a substantial effect upon plant growth and development and plant interactions in the field (Bogenrieder and Klein 1982). Observations on the promotion of flowering in some alpine plants (Caldwell 1968) and the reduction of solar injury in certain melon species (Lipton and O'Grady 1980) after exclusion of solar UV-B radiation suggest some effect. Additional evidence concerning the effect of ambient solar UV-B on plant competition will be discussed later. However, the exclusion of solar UV-B radiation can sometimes have no effect upon the plants being examined. Becwar et al. (1982) found no change in the dry weight of wheat, potato and radish monocultures grown under filters which excluded UV-B relative to control plants under UV-B transparent filters $(55 \mathrm{~mW}$ $\mathrm{m}^{-2}$ at solar noon using the generalized plant action spectrum) at a high elevation site in Colorado. Only wheat plant height increased significantly when UV-B was excluded.

Current concern over the potential anthropogenic depletion of the stratospheric ozone layer (NAS 1979, 1982) has led to many studies on the effects upon plants of the expected resulting increase in ultraviolet-B radiation. The currently predicted 7 to $16 \%$ ozone layer reduction (NAS 1979,1982 ) could result in a significant increase in the biologically effective UV-B radiation flux (Caldwell 1977). This would enhance the importance of UV-B radiation as an environmental stress. Many higher plants have been shown to exhibit widely different sensitivity to UV-B radiation (Biggs et al. 1975, Caldwell 1977, Biggs and Kossuth 1978, Kossuth and Biggs 1981). Thus, this increase in UV-B radiation, over a relatively short evolutionary time span (50-100 years; NAS 1979,1982 ) could lead to changes in competition within plant communities through the differential resistance to UV-B of competing plant species. There is substantial evidence that simulated increases in UV-B radiation can alter plant growth and physiological processes under laboratory and greenhouse conditions (Sisson and Caldwell 1977, Biggs and Kossuth 1978, Kossuth and Biggs 1981), but few field studies on the effects of increased ultraviolet radiation on plant competition have been undertaken (Fox and Caldwell 1978).

Abbreviations - UV-B, ultraviolet-B.

\section{Intraspecific competition}

Intraspecific competition is a situation in which two or more individuals of the same species compete for limited resources. The importance of intraspecific competition to plants in a community is dependent upon the relative impacts of intraspecific and interspecific interactions as well as the overall importance of competitive interactions within the community. Intraspecific interactions become increasingly important in com- 


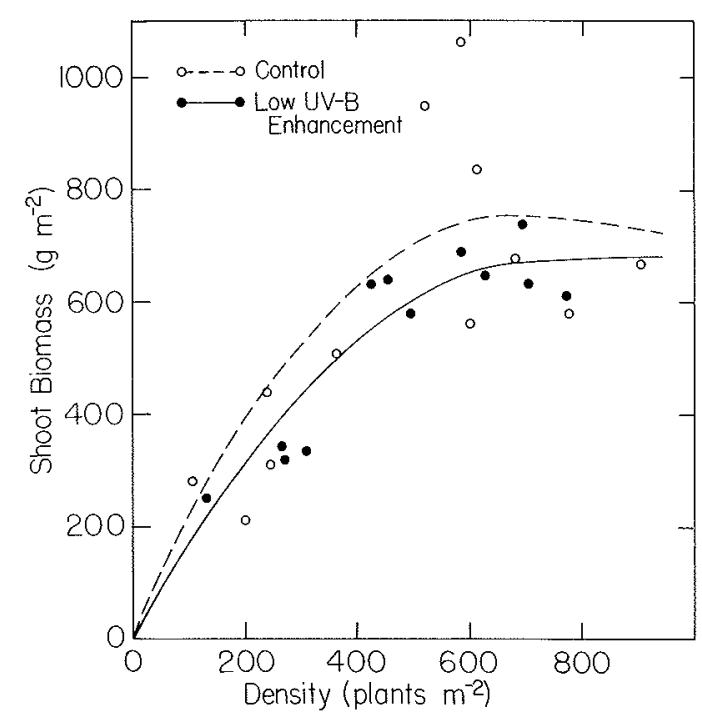

Fig. 1. Relationships between the shoot biomass $\left(\mathrm{g} \mathrm{m}^{-2}\right)$ of wheat plants produced under control (solar UV-B) and treatment $(16 \%$ ozone layer reduction simulation using the generalized plant action spectrum) UV-B irradiance conditions and total monoculture plot density (plants $\mathrm{m}^{-2}$ ). Higher monoculture densities provide higher intensities of intraspecific competition. The curves are significant $(P<0.01)$ quadratic regressions, but are not significantly different from each other. The data were taken at the final harvest in 1981 (August 24). The data are from W. G. Gold, thesis.

munities which are largely monospecific, such as agricultural systems. On the other hand, communities characterized by a high degree of species diversity, such as low latitude tropical forests, have a relatively low potential for intraspecific interactions.

Many studies have examined the effect of UV-B radiation on monoculture production of plants (Biggs et al. 1975, Biggs and Kossuth 1978). However, in order to assess the impact of UV-B upon intraspecific competitive response, a gradient of monoculture densities is necessary. Data from our recent field experiments (W. G. Gold, 1983. Thesis, Utah State Univ., Logan, Utah, USA) suggest that increased UV-B (simulating that of a $16 \%$ reduction in the ozone layer using the generalized plant action spectrum; Caldwell et al. 1983) has no effect upon plant response to a gradient in intraspecific intensity for wheat (Triticum aestivum L. cv. Bannock), wild oat (Avena fatua L.) or jointed goatgrass (Aegilops cylindrica Host). Figure 1 shows data from these experiments for wheat monoculture production at various densities with and without the above UV-B enhancement in the field during 1981 . The regression curves represent the response $(P<0.01)$ of wheat production to changes in density found at the final harvest (August 24, 1981). The response curves for the UV-B enhanced plots and control plots are not significantly different. The data for wild oat and jointed goatgrass monocultures were very similar. Thus, under this range of den- sities and particular environmental conditions, an increase in UV-B radiation did not affect the intraspecific competitive response of these three grass species. This suggests that the impact of an increase in UV-B radiation upon wheat-based agricultural systems may be of little consequence in terms of plant intraspecific competitive response.

\section{Interspecific competition}

Competition between different species is a potential selective force which may influence plant community structure and composition. The actual degree to which past and present interspecific competitive interactions influence plant community structure and species coexistence is currently under debate (Wiens 1977, Connell 1980, Fowler 1981, 1982, Grace and Wetzel 1981, Grubb et al. 1982). Connell (1975) has proposed that competitive interactions could be expected to be more common in natural systems characterized by a moderate degree of physicochemical stress. In environments of extreme physicochemical stress, biotic interactions such as competition are often less common. In environments of low physicochemical stress and thus where plant requirements become less restricted, biotic interactions other than competition become relatively more important (e.g. parasitism, herbivory). In addition, environments are highly variable in space and time, and this variability (including major perturbations) could alter the relative importance of the physicochemical and biotic stresses. This variability may also play a major role in the maintenance of species coexistence (Wiens 1977), reducing the importance of interspecific competition in this function.

The existence and importance of interspecific competition is well documented in agricultural situations. Bell and Nalewaja (1968) and Henson and Jordan (1982) have shown that significant decreases in wheat and barley yields occur in the presence of wild oat. McWhorter and Patterson (1980) reviewed many studies that show reductions in soybean yields as a result of the presence of weeds. However, the existence of interspecific plant competition in natural plant communities has rarely been documented through experimental field manipulations (Connell 1980, Grace and Wetzel 1981).

The impact of ambient solar UV-B radiation (as exists without ozone reduction) on interspecific plant competition has been investigated by Bruzek (B. Bruzek, 1977. Staatsexamensarbeit, Univ. of Freiburg, West Germany) and Kiliani (S. Kiliani, 1978. Staatsexamensarbeit, Univ. of Freiburg, West Germany). These experiments were carried out in a region of relatively low ambient solar UV-B flux (Freiburg, West Germany, $200 \mathrm{~m}$ altitude, $48^{\circ} \mathrm{N}$. latitude), using ecologically relevant species pairs. There are no measured data available for integrated daily UV radiation 


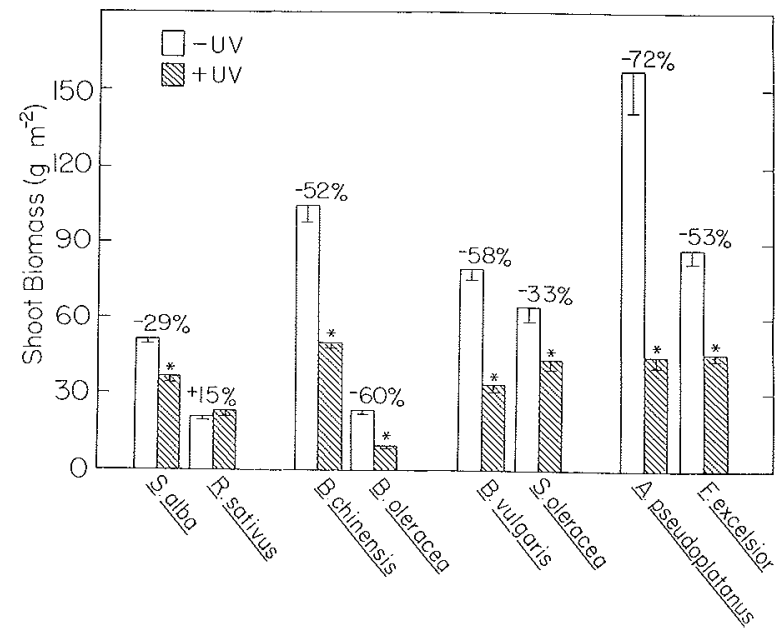

Fig. 2. Shoot biomass $\left(\mathrm{g} \mathrm{m}^{-2}\right)$ produced by species in competition experiments using species pairs without solar UV-B (-UV) and with a rough approximation of solar UV-B irradiance at Freiburg, West Germany (+UV) in the greenhouse. Error bars indicate one SE. Percentage changes in shoot biomass produced under solar UV-B relative to no solar UV-B is indicated above the bars for each species. The asterisks indicate a significant $(P<0.05)$ effect of solar UV-B radiation on shoot biomass production of a species by Student's t-test. The species pairs are: Sinapis alba : Raphanus sativus, Brassica chinensis : Brassica oleracea, Beta vulgaris : Spinacia oleracea and Acer pseudoplatanus : Fraxinus excelsior. The data are taken from B. Bruzek, Staatsexamensarbeit.

flux at Freiburg. However, calculations with the Green et al. (1980) model indicate that this flux (weighted with the generalized plant action spectrum) is about $32 \%$ lower than that calculated for Logan, Utah $\left(40^{\circ} \mathrm{N}\right.$. latitude, $1500 \mathrm{~m}$ elevation) at the time of maximum solar radiation. Caldwell et al. (1980) give a measured value of $1462 \mathrm{~J} \mathrm{~m}^{-2}$ day $^{-1}$ for UV radiation weighted with the generalized plant action spectrum at Logan, Utah under those conditions. In greenhouse experiments, Bruzek (B. Bruzek, 1977. Staatsexamensarbeit, Univ. of Freiburg, West Germany) found differential changes in the relative dry matter production of some pairs of species grown together under UV-B lamps very roughly approximating an ambient solar UV-B flux compared to control mixtures grown without any UV-B irradiation (Fig. 2). In three of the four species pairs shown in Fig. 2 (Sinapis alba: Raphanus sativus, Beta vulgaris: Spinacia oleracea, Acer pseudoplatanus : Fraxinus excelsior), there was a significant change in the relative dry matter production of the two species. The Brassica chinensis : Brassica oleracea mixture did not show this change. Field experiments, involving the exclusion of solar UV-B, also showed changes in the relative dry matter production between the species of each pair tested (Fig. 3). The true nature of the effect of solar UV-B on interspecific competition is difficult to ascertain without data on the monoculture response of the

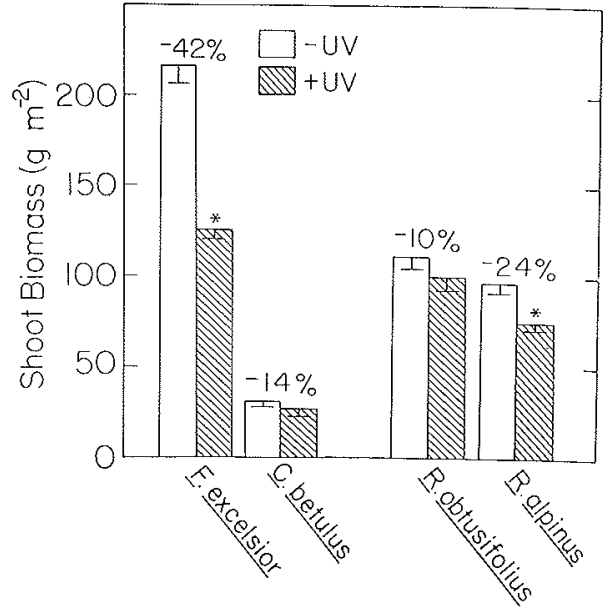

Fig. 3. Shoot biomass $\left(\mathrm{g} \mathrm{m}^{-2}\right)$ produced by species in competition experiments using species pairs without solar UV-B (-UV) and with solar UV-B irradiance (+UV) in the field at Freiburg, West Germany. Error bars indicate one SE. The percentage change in shoot biomass produced under solar UV-B relative to no solar UV-B is given above the bars for each species. The asterisks indicate a significant $(P<0.05)$ effect of solar UV-B radiation on shoot biomass production of a species by Student's t-test. The species pairs are: Fraxinus excelsior: Carpinus betulus, and Rumex obtusifolius : Rumex alpinus. The data are taken from B. Bruzek, Staatsexamensarbeit.

two species to solar UV-B stress. For instance, the differential response of the species observed in the mixtures could be the same as that of the species in monocultures. Thus, the response of each of the species in mixture may be simply a direct physiological response to the UV-B stress with both the existence of competitive interactions and the possible effect of UV-B upon these interactions being uncertain. The only monoculture data taken were for Rumex obtusifolius and Rumex alpinus (at different densities than in the mixture). The changes in shoot biomass of each species under UV-B in monoculture $[R$. obtusifolius $(-13 \%)$ and $R$. alpinus $(-20 \%)]$ were similar to those seen for the species under UV-B in mixture. This suggests that UV-B had only a direct physiological effect upon these two species in mixture. Kiliani (S. Kiliani, 1978. Staatsexamensarbeit, Univ. of Freiburg, West Germany), in similar field experiments, also found significant changes in the relative biomass production of different species pairs under ambient solar UV-B radiation as compared to pairs grown without UV-B radiation (Fig. 4). The relative changes in shoot biomass of these species in monoculture under UV-B relative to no UV-B [corresponding to each of the mixture trials: $T$. vulgare $(-38 \%)$ and $S$. sylvaticus $(-35 \%), V$. phlomoides $(+18 \%)$ and $T$. officinale $(-16 \%), V$. phlomoides $(+9 \%)$ and $B$. perennis $(-22 \%)]$ were different than when they were grown in pairs (Fig. 4). The experiments of Bruzek and Kiliani were recently published, in part, by Bogenrieder and 


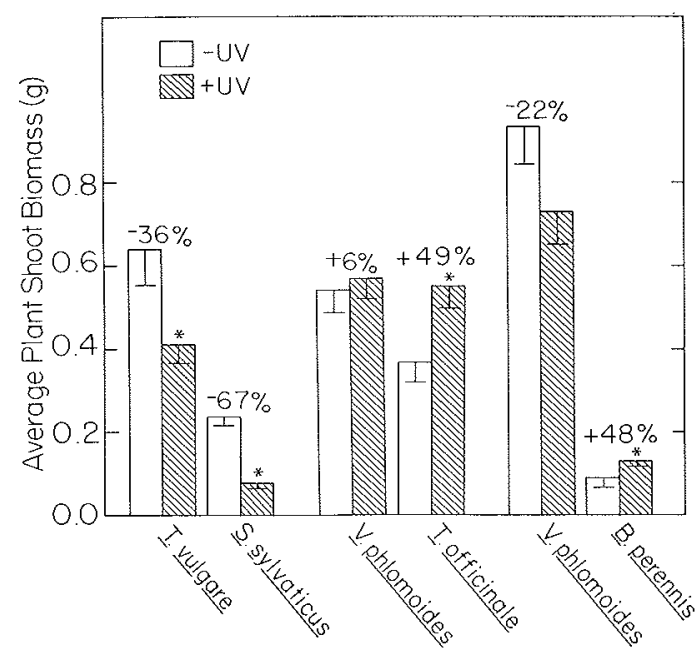

Fig. 4. Average plant shoot biomass (g) produced by species in competition experiments using species pairs without solar UV-B (-UV) and with solar UV-B irradiance (+UV) in the field at Freiburg, West Germany. The error bars indicate one $\mathrm{SE}$. The percentage change in shoot biomass produced under solar UV-B relative to no solar UV-B is given for each species. The asterisks indicate a significant $(P<0.05)$ effect of solar UV-B on shoot biomass production of a species by Student's t-test. The species pairs are: Tanacetum vulgare : Senecio sylvaticus, Verbascum phlomoides: Taraxacum officinale, and Verbascum phlomoides : Bellis perennis. The data are taken from S. Kiliani, Staatsexamensarbeit.

Klein (1982). The results suggest that ambient solar UV-B (as exists without ozone depletion) has a significant effect upon the competitive interaction of species pairs. The total shoot biomass production of the species pairs was reduced under solar UV-B relative to pairs grown without UV-B in all cases except one (Verbascum phlomoides: Taraxicum officinale, Fig. 4).
Caldwell (1977) has hypothesized that an increase in incident UV-B radiation could alter the competitive interactions within plant communities because of the differential resistances of the component species to increases in UV-B. Fox and Caldwell (1978) examined the effect of an artificial increase in UV-B radiation on the competitive interactions of selected species pairs. Solar UV-B radiation was supplemented with sunlamps (Sisson and Caldwell 1975) to approximate the daily dose of weighted UV-B irradiance expected with a $40 \%$ reduction in the ozone layer, using the generalized plant action spectrum (Caldwell 1971). Three types of species associations were examined: agricultural crops and associated weeds, montane forage species, and disturbed area weedy associates (Tab. 1). The mixtures were sown in a modified deWit (1960) replacement series design in pots, which were placed in the field for the duration of the experiment.

The deWit (1960) replacement series is a model of plant competition in which plants compete directly for space and limited plant requirements within that space. The experimental design maintains a constant overall plant density while varying the proportion of the two species present within a given area. The competitiveness of a species relative to the other species of a particular pair is evaluated by comparing its performance in the mixtures to its performance in monocultures of the same density.

Relative crowding coefficients $\left(\mathrm{k}_{12}\right)$ were used to analyze the competitive situations (Harper 1977). The relative crowding coefficient is a relative measure of the competitive ability of one species when it is grown in mixture with a second species. The relative crowding coefficient can be calculated by:

$\mathrm{k}_{12}=\frac{\mathrm{O}_{1} \cdot \mathrm{M}_{2} \cdot \mathrm{Z}_{2}}{\mathrm{O}_{2} \cdot \mathrm{M}_{1} \cdot \mathrm{Z}_{1}}$

Tab. 1. Relative crowding coefficients based upon shoot biomass for competing species pairs under ambient solar UV-B irradiance (control) and enhanced UV-B simulating a $40 \%$ ozone layer reduction (using the generalized plant action spectrum). The plant associations which the groups of species pairs represent are given. The letter ' $\mathrm{a}$ ' denotes a significant $(P<0.05)$ difference between treatment and control relative crowding coefficients for a particular species pair. The data are taken from Fox and Caldwell (1978)

\begin{tabular}{|c|c|c|c|c|}
\hline \multirow[t]{2}{*}{ Plant association } & \multicolumn{2}{|c|}{ Competing species pair } & \multicolumn{2}{|c|}{ Relative crowding coefficient } \\
\hline & Species 1 & Species 2 & Control & Enhanced UV-B \\
\hline $\begin{array}{l}\text { Agricultural crops } \\
\text { and associated } \\
\text { weeds }\end{array}$ & $\begin{array}{l}\text { Alyssum alyssoides } \mathrm{L} . \\
\text { Amaranthus retroflexus } \mathrm{L} \text {. } \\
\text { Amaranthus retroflexus } \mathrm{L} . \\
\text { Setaria glauca } \text { (L.) Beauv. }\end{array}$ & $\begin{array}{l}\text { Pisum sativum } \mathrm{L} . \\
\text { Medicago sativa } \mathrm{L} . \\
\text { Allium cepa } \mathrm{L} . \\
\text { Trifolium pratense } \mathrm{L} .\end{array}$ & $\begin{array}{l}0.34 \\
3.56 \\
1.89 \\
2.06\end{array}$ & $\begin{array}{c}0.25 \\
0.73^{\mathrm{a}} \\
2.01 \\
18.74\end{array}$ \\
\hline $\begin{array}{l}\text { Montane forage } \\
\text { species }\end{array}$ & Poa pratensis L. & Geum macrophyllum Willd. & 0.85 & $2.28^{\mathrm{a}}$ \\
\hline $\begin{array}{l}\text { Disturbed area } \\
\text { weedy associates }\end{array}$ & $\begin{array}{l}\text { Bromus tectorum } \mathrm{L} \text {. } \\
\text { Plantago patagonica Jacq. }\end{array}$ & $\begin{array}{l}\text { Alyssum alyssoides } \mathrm{L} . \\
\text { Lepidium perfoliatum } \mathrm{L} .\end{array}$ & $\begin{array}{l}6.35 \\
0.75\end{array}$ & $\begin{array}{l}1.63 \\
0.68\end{array}$ \\
\hline
\end{tabular}




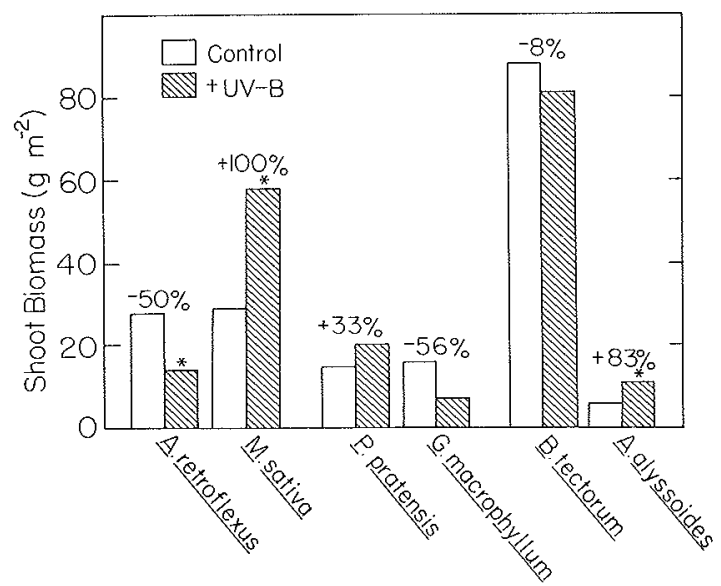

Fig. 5. Shoot biomass $\left(\mathrm{g} \mathrm{m}^{-2}\right)$ produced by species in competition experiments with species pairs under solar UV-B irradiance (control) and UV-B irradiance enhanced (+UV-B) to approximate a $40 \%$ ozone layer reduction (using the generalized plant action spectrum) in the field. The percentage change in shoot biomass produced under enhanced UV-B relative to solar UV-B is given above the bars for each species. The asterisks indicate a significant $(P<0.05)$ effect of UV-B enhancement for that species. The species pairs are: Amaranthus retroflexus : Medicago sativa, Poa pratensis : Geum macrophyllum, and Bromus tectorum: Alyssum alyssoides. The data are taken from Fox and Caldwell (1978).

where $M$ is the yield of the particular species (1 or 2$)$ in monoculture, $\mathrm{O}$ is the yield of the particular species in mixture, and $\mathrm{Z}$ is the number of plants of that particular species in the mixture. Calculated in this manner, when $\mathrm{k}_{12}$ is greater than 1.0, the first species has a competitive advantage and when $\mathrm{k}_{12}$ is less than 1.0 , the second species has a competitive advantage. When $\mathrm{k}_{12}$ equals 1.0 neither species is at a competitive advantage. The monoculture and mixture yields can be measured using any parameter that gives an appropriate reflection of species' competitive ability (e.g. biomass, seed production).

The relative crowding coefficients based upon total aboveground biomass (Tab. 1) indicate that there was a significant shift in the competitive balance of two of the species pairs examined (Amaranthus retroflexus: Medicago sativa; Poa pratensis : Geum macrophyllum). However, the total aboveground biomass production of the mixtures (except Pisum sativum: Alyssum alyssoides) was not significantly reduced under UV-B enhancement. In some mixtures this was due to an increase in shoot biomass of one species and a reduction in the shoot biomass of the other species (Fig. 5).

Fox and Caldwell (1978) found that the relative proportion of interspecific and intraspecific competition had no consistent effect on the UV-B suppression of individual species' biomass. Some of the species showed their most significant biomass suppression due to UV-B under a high proportion of interspecific competition, while other species showed their highest UV-B biomass suppression under a high proportion of intraspecific competition. The relative competitive effectiveness of individuals of one species upon that same species (intraspecific) or of individuals of another species upon that original species (interspecific) depends upon the particular species and situation (e.g. Haizel and Harper 1973). Hence, the total degree of competitive stress present (and its ability to alter the effect of the UV-B stress upon individuals) at a certain proportion of interspecific and intraspecific interactions depends, in part, upon the particular species involved. It is still not clear if a relatively high degree of total competitive stress would enhance or mask the effects of UV-B stress. In the case of intraspecific competition only, the total amount of competitive stress present, at least over a limited range, did not alter the effect of UV-B stress (Fig. 1).

Recently, we have undertaken field studies to examine the effect of an increase in $U V-B$ radiation on the competitive interactions in agricultural plant populations. We examined the interactions of wheat (Triticum aestivum L. cv. Bannock) and a common weedy competitor, wild oat (Avena fatua L.). In the spring of 1982, the two species were sown in a deWit (1960) replacement series in field plots under UV lamp systems whose radiant emittance changes in accordance with fluctuations in ambient solar UV flux (Caldwell et al. 1983). The treatment lamp systems provided two levels of UV-B enhancement, simulating a $16 \%$ and a $40 \%$ reduction in the ozone layer (using the generalized

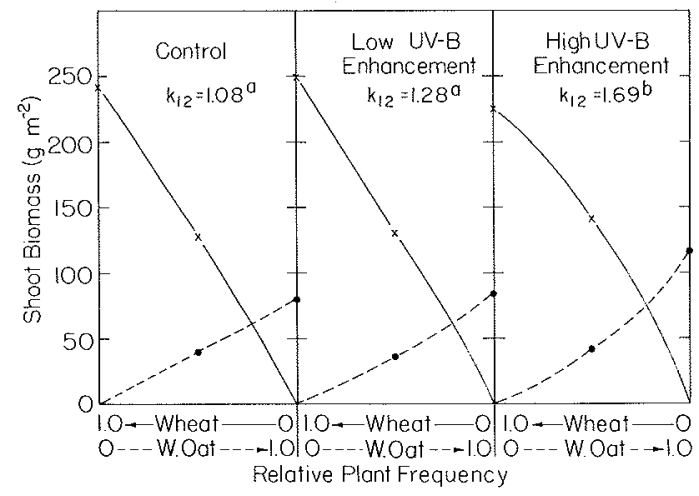

Fig. 6. Replacement series diagrams of shoot biomass $\left(\mathrm{g} \mathrm{m}^{-2}\right)$ for wheat (Triticum aestivum L. cv. Bannock) and wild oat (Avena fatua L.) at the final harvest in 1982 (August 2). The species were under three levels of UV-B irradiation: solar UV-B irradiance (control), a simulated $16 \%$ ozone layer reduction (low UV-B enhancement) and a simulated $40 \%$ ozone layer reduction (high UV-B enhancement). The simulations of ozone reduction were based upon the generalized plant action spectrum. The relative crowding coefficients $\left(k_{12}\right)$ of species 1 (wheat) with respect to species 2 (wild oat) suggest an increasing competitive advantage for wheat with increasing UV-B enhancement. This increase is statistically significant $(P<$ 0.05 ) by ANOVA only for the high UV-B enhancement. The data are from W. G. Gold, thesis. 
plant action spectrum). Detailed radiation methodology and spectral irradiance data are presented by Caldwell et al. (1983). The aboveground portions of the plants were harvested at the end of the growing season and the aboveground biomass was determined for each species, Replacement series diagrams and relative crowding coefficients (deWit 1960) indicate that UV-B enhancement altered the competitive balance (in terms of aboveground biomass) in favor of wheat at the end of the growing season (Fig. 6). The increasing convexity of the wheat curve under UV-B enhancement reflects a greater proportional contribution of wheat to the shoot biomass of the 50:50 mixture than its proportional presence in the mixture $(50 \%)$. This suggests an increase in competitive ability for wheat relative to wild oat based upon shoot biomass production. This was contrary to the results for wheat:wild oat mixtures under a simulated $16 \%$ ozone reduction UV-B treatment in 1981 (W. G. Gold, thesis), where the competitive balance was shifted in favor of wild oat. In 1981, the species were planted much later (late June) than in 1982 (late April). Therefore, in 1981, the seedlings, which is likely to be the life stage most sensitive to

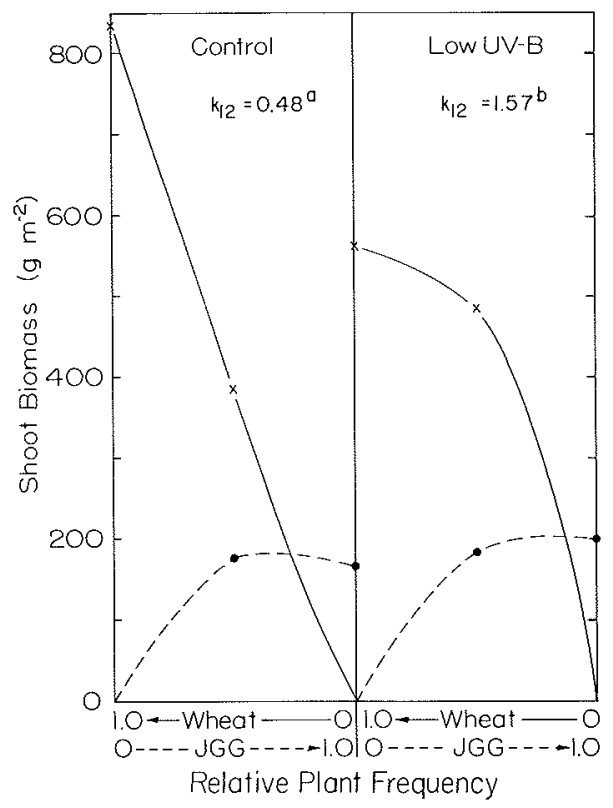

Fig. 7. Replacement series diagrams of shoot biomass $\left(\mathrm{g} \mathrm{m}^{-2}\right)$ for wheat (Triticum aestivum L. cv. Bannock) and jointed goatgrass (Aegilops cylindrica Host) at the final harvest in 1981 (August 24). The pairs were under two levels of UV-B irradiation: solar UV-B irradiance (control) and a simulated $16 \%$ ozone layer reduction (low UV-B enhancement). The simulation of ozone reduction was based upon the generalized plant action spectrum. The relative crowding coefficients $\left(\mathrm{k}_{12}\right)$ of species 1 (wheat) with respect to species 2 (jointed goatgrass) suggest an increased competitive ability for wheat under low UV-B enhancement relative to control conditions. This increase is statistically significant $(P<0.05)$ by multiple regression analysis. The data are from W. G. Gold, thesis.
UV-B, were exposed to considerably higher levels of water stress, ambient solar UV-B stress, and high temperature stress. As in the study by Fox and Caldwell (1978), the total aboveground biomass of wheat:wild oat mixtures was not altered by UV-B enhancement despite changes in competitive interactions (W. G. Gold, thesis).

In 1981 the competitive interactions of wheat and jointed goatgrass (Aegilops cylindrica Host) were examined under a treatment simulation of a $16 \%$ ozone layer reduction (using the generalized plant action spectrum; W. G. Gold, thesis). The competitive balance was shifted in favor of wheat under UV-B enhancement relative to the control plots (Fig. 7). This was contrary to the depression of the competitive ability of wheat in wheat:wild oat mixtures under UV-B enhancement in 1981. Thus, it is clear that the effect of UV-B enhancement upon a species' competitive ability depends, in part, upon the particular species it is competing with and their relative sensitivities to UV-B. The total aboveground biomass of wheat:jointed goatgrass mixtures was not altered by UV-B enhancement.

\section{Conclusions}

There is evidence that current levels of solar UV-B radiation can affect the relative biomass production of certain species pairs in the greenhouse and the field (B. Bruzek, Staatsexamensarbeit, S. Kiliani, Staatsexamensarbeit, Bogenrieder and Klein 1982). Bogenrieder and Klein (1982) suggest that this was due to the differential height of the competitors. The smaller species usually benefited under UV-B stress, presumably as a result of a relatively reduced UV-B flux in the shade of the taller species. This suggests that ambient solar $\mathrm{UV}-\mathrm{B}$, in an area of not particularly intense UV-B, can alter plant interspecific competitive relationships. However, the lack of complete monoculture response data leaves the existence of interspecific competitive interactions between species of some pairs open to question. In addition, ambient solar UV-B significantly depressed total biomass production in mixtures (Bogenrieder and Klein 1982).

There is substantial evidence that enhanced levels of UV-B can alter the competitive interactions of some species pairs. A high level of UV-B enhancement (approximating a $40 \%$ ozone layer reduction) changed the competitive balance of some species pairs grown in pots under field conditions (Fox and Caldwell 1978). A more realistic level of UV-B enhancement (simulating a $16 \%$ reduction in the ozone layer; NAS 1979, 1982) also changed the competitive interactions in certain agricultural species pairs in the field (W. G. Gold, thesis).

In many of the situations where competitive balance of species pairs was altered by UV-B enhancement, an increase in biomass production of the apparently more resistant species was observed (Fox and Caldwell 1978, 
W. G. Gold, thesis). This was accompanied by a decrease in the biomass production of the apparently more sensitive species. Thus, the apparent beneficial effect of enhanced UV-B radiation for one species may be the result of decreased competitive pressure from a more sensitive competitor. In addition, the species pairs did not exhibit a decrease in total biomass production under UV-B enhancement. This supports Caldwell's hypothesis (1977) that because of the subtle nature of UV-B radiation stress, an increase in UV-B may be more likely to alter competitive interactions within an ecosystem than to alter the total primary productivity of that system. However, a decrease in UV-B stress, through solar UV-B exclusion, resulted in an increase in total mixture production, as both competitors responded with an increase in shoot biomass (Bogenrieder and Klein 1982).

The overall production of some species pairs appears to have been constrained by current levels of solar UV-B. However, increases in this UV-B stress did not result in a further decrease in overall production of other species pairs, because of compensatory biomass changes between apparently differentially sensitive competitors. Unfortunately, no species pairs have been examined both without UV-B and under UV-B enhancement to test this observation.

Temporal variability in environments can change the nature of competitive interactions and hence, the impact of a UV-B enhancement upon those interactions. The nature of the entire stress complex during the young life stages of competing species may be especially critical in altering the effect of increases in UV-B on interspecific competition. When the seedlings of wheat: wild oat mixtures emerged under conditions of high physicochemical stress, wild oat exhibited an increase in competitive ability under enhanced UV-B (W. G. Gold, thesis). However, when the seedlings emerged under conditions of relatively lower physicochemical stress, wheat exhibited an increased competitive ability under UV-B enhancement.

Many authors have recently suggested that the role of plant competition in the maintenance of species coexistence and community structure in many natural plant communities may be relatively minor (Wiens 1977 , Connell 1980, Fowler 1981, Fowler and Antonovics 1981, Pickett 1980). Other factors, such as high physicochemical stress, environmental variability (spatial and temporal), major perturbations (non-equilibrium systems), and functional niche differentiation, have been suggested to be important. The impact of an increase in UV-B radiation may not be important in natural communities where plant competition has little effect upon such community properties. However, the impact of UV-B radiation upon agricultural communities could have serious consequences since harvest yield quantity and quality are often influenced by interactions with weedy species (Bell and Nalewaja 1968, McWhorter and Patterson 1980).

\section{Implications for further research}

The impact of UV-B radiation upon plant competition in natural communities and ecosystems is difficult to ascertain from laboratory or greenhouse experiments. Field experiments are necessary to obtain ecologically relevant results. Field lamp systems providing realistic, modulated UV-B supplements (Caldwell et al. 1983) are also desirable for studies concerning the effects of increased UV-B radiation resulting from predicted stratospheric ozone depletion. The initial work on the interaction of plant competition and UV-B radiation (B. Bruzek, Staatsexamensarbeit, Fox and Caldwell 1978, S. Kiliani, Staatsexamensarbeit, W. G. Gold, thesis) has been progressively more ecologically realistic, but other considerations are still necessary.

Competition experiments with species pairs are relatively easy to interpret but are ecologically realistic only in communities that are characterized by one or more pairs of competing species, such as a wheat field with a serious infestation of wild oat. In many communities, complex species interrelationships, often termed diffuse competition, invalidate the concept of discrete, competing species pairs (e.g. Fowler 1981). Thus, experiments involving multiple species would be useful in assessing the effect of increased UV-B radiation on competition within many plant communities. The relative ecological performance of individual species within multiple species mixtures exposed to different levels of nutrient stress has been assessed by Austin and Austin (1980). This approach to examining the effect of a changing stress upon individual species within a community environment (Austin 1982) should be considered also for the evaluation of the effects of UV-B radiation. In addition, the impact of organisms from other trophic levels, such as herbivores, should also be considered in such experiments. The possible interactions of UV-B radiation and soil microbes or plant pathogens have also been neglected. Fox and Caldwell (1978) speculated about the suppression of plant pathogens by UV-B as a possible explanation for observed increases in both species of a mixture (Bromus tectorum : Alyssum alyssoides) under UV-B enhancement. The possibility of these types of interactions should not be overlooked in attempts to assess the effect of increased UV-B radiation upon plant communities.

Although information on the belowground systems of plants can be difficult to obtain in field situations, knowledge of these interactions and responses are necessary to properly evaluate the response of competitive situations to changes in any physicochemical stress. For instance, results that indicate changes in aboveground biomass under UV-B radiation enhancement could be due to a change in the allocation of plant resources to aboveground versus belowground biomass rather than a decrease in total plant biomass.

Most of the studies on the interaction of plant competition and UV-B radiation have assessed competitive 
ability on the basis of shoot biomass (B. Bruzek, Staatsexamensarbeit, Fox and Caldwell 1978, S. Kiliani, Staatsexamensarbeit). However, in order to assess the long term competitive situation, an analysis of competitive ability based upon reproductive success is also necessary (Harper 1977). Preliminary data from our field experiments indicate that the competitive ability of wheat based upon reproductive biomass production increased relative to wild oat under UV-B enhancement in 1982 (W. G. Gold, thesis). This parallels the effect of UV-B enhancement upon competitive ability based upon shoot biomass production, but it is only an isolated case.

Finally, long term studies of natural plant communities are crucial for a more realistic assessment of the impacts of UV-B radiation. The relative species composition of many natural plant communities is highly variable through time (Grubb et al. 1982), partly as a result of changes in such physicochemical stresses. The effect of increased UV-B radiation on interactions within a plant community is likely to change as the relative species composition of that community and other physicochemical stresses change over time.

Acknowledgements - The current research was supported by the United States Environmental Protection Agency through Contract EPA-C-80816010 to Utah State University, but it has not been subjected to the Agency's required peer and policy review and therefore does not reflect the views of the Agency and no official endorsement should be inferred. The first author would like to gratefully acknowledge the support of a United States National Science Foundation Graduate Fellowship during the research and formulation of this paper. The technical assistance and advice of Steve Flint during the recent field studies is also gratefully acknowledged.

\section{References}

Austin, M. P. 1982. Use of a relative physiological performance value in the prediction of performance in multispecies mixtures from monoculture performance. $-\mathrm{J}$. Ecol. $70: 559-570$

- \& Austin, B. O. 1980. Behaviour of experimental plant communities along a nutrient gradient. - J. Ecol. 68: 891-918.

Becwar, M. R., Moore, F. D. III. \& Burke, M. J. 1982. Effects of deletion and enhancement of ultraviolet-B (280-315 $\mathrm{nm}$ ) radiation on plants grown at $3000 \mathrm{~m}$ elevation. - J. Am. Soc. Hortic. Sci. 107: 771-774.

Bell, A. R. \& Nalewaja, J. D. 1968. Competition of wild oat in wheat and barley. - Weed Sci. 16: 505-508.

Bennett, J. P. \& Runeckles, V. C. 1977. Effects of low levels of ozone on plant competition. - J. Appl. Ecol. 14: 877-880.

Biggs, R. H. \& Kossuth, S. V. 1978. Impact of solar UV-B radiation on crop productivity, - In Final Report of UV-B Biological and Climate Effects Research, Non-Human Organisms. U.S. Environmental Protection Agency Report No. EPA-IAG-D6-0618. pp. II-1 to II-79. Washington D.C.
-- Sisson, W. B. \& Caldwell, M. M. 1975. Response of higher terrestrial plants to elevated UV-B irradiance. - In Impacts of Climatic Change on the Biosphere. Climatic Impact Assessment Program Monograph 5. Report Number DOT-TST-75-55. (D. S. Natchway, M. M. Caldwell and R. H. Biggs, eds), pp. $4-34$ to $4-50$. United States Department of Transportation, Springfield, VA.

Björkman, O. 1981. Ecological adaptation of the photosynthetic apparatus. - In Photosynthesis VI. Photosynthesis and Productivity, Photosynthesis and Environment ( G. Akoyunoglou, ed.), pp. 191-202. Balaban Intl. Science Services, Philadelphia, PA. ISBN 0-86689-011-4.

Bogenrieder, A. \& Klein, R. 1982. Does solar UV influence the competitive relationship in higher plants? - In The Role of Solar Ultraviolet Radiation in Marine Ecosystems (J. Calkins, ed.), pp. 641-649. Plenum Press, New York. ISBN 0-306-40909-7.

Caldwell, M. M. 1968. Solar ultraviolet radiation as an ecological factor for alpine plants. - Ecol. Monogr. 38: 243-268.

- 1971. Solar ultraviolet radiation and the growth and development of higher plants. - In Photophysiology (A. C. Giese, ed.), Vol. 6, pp. 131-177. Academic Press, New York

- 1977. The effects of solar UV-B radiation $(280-315 \mathrm{~nm})$ on higher plants: Implications of stratospheric ozone reduction. - In Research in Photobiology (A. Castellani, ed.), pp. 597-607. Plenum Publishing Co., London. ISBN 0-306-31034-1.

- 1981. Responses to solar ultraviolet radiation. - In Physiological Plant Ecology: Responses to the Physical Environment. Encyclopedia of Plant Physiology, New series (O. L. Lange, P. S. Nobel, C. B. Osmond and H. Ziegler, eds), Vol. 13A, pp. 169-198. Springer-Verlag, New York. ISBN 3-540-10763-0.

- , Robberecht, R. \& Billings, W. D. 1980. A steep latitudinal gradient of solar ultraviolet-B radiation in the arcticalpine life zone. - Ecology 61: 600-611.

- , Gold, W. G., Harris, G. \& Ashurst, C. W. 1983. A modulated lamp system for solar UV-B (280-320 nm) supplementation studies in the field. - Photochem. Photobiol. 37 : 479-485.

- , Robberecht, R., Nowak, R. S. \& Billings, W. D. 1982. Differential photosynthetic inhibition by ultraviolet radiation in species from the arctic-alpine life zone. - Arctic Alp. Res. 14: 195-202.

Connell, J. H. 1975. Some mechanisms producing structure in natural communities: A model and evidence from field experiments. - In Ecology and Evolution of Communities (M. L. Cody and J. M. Diamond, eds), pp. 460-490. Harvard Univ. Press, Cambridge, MA. ISBN 0-674-22444-2.

- 1980. Diversity and the coevolution of competitors, or the ghost of competition past. - Oikos 35: 131-138.

deWit, C. T. 1960. On competition. - Versl. Landbowk. Onderzoek. The Hauge. 66: 1-82.

Fowler, N, 1981. Competition and coexistence in a North Carolina grassland. II. The effects of the experimental removal of species. - J. Ecol. 69: 843-854.

- 1982. Competition and coexistence in a North Carolina grassland. III. Mixtures of component species. $-\mathrm{J}$. Ecol. 70: 77-92.

- \& Antonovics, J. 1981. Competition and coexistence in a North Carolina grassland. I. Patterns in undisturbed vegetation. - J. Ecol. 69: 825-841.

Fox, F. M. \& Caldwell, M. M. 1978. Competitive interaction in plant populations exposed to supplementary ultraviolet-B radiation. - Oecologia. 36: 173-190.

Grace, J. B. \& Wetzel, R. G. 1981. Habitat partitioning and competitive displacement in cattails (Typha): Experimental field studies. - Am. Nat. 118: 463-474. 
Green, A. E. S., Cross, K. R. \& Smith, L. A. 1980. Improved analytic characterization of ultraviolet skylight. - Photochem. Photobiol. 31: 59-65.

Grime, J. P. 1977. Evidence for the existence of three primary strategies in plants and its relevance to ecological and evolutionary theory. - Am. Nat. 111: 1169-1194.

- 1979. Plant Strategies and Vegetation Processes. - John Wiley \& Sons, New York. pp. 1-36. ISBN 0-471-99695-5.

Grubb, P. J., Kelley, D. \& Mitchley, J. 1982. The control of relative abundance in communities of herbaceous plants. In The Plant Community as a Working Mechanism. Special Publications Series of the British Ecological Society Number 1 (E. I. Newman, ed.), pp. 79-98. Blackwell Sci. Publications, London. ISBN 0-632-00839-3.

Haizel, K. A. \& Harper, J. L. 1973. The effects of density and the timing of removal on interference between barley, white mustard and wild oats. - J. Appl. Ecol. 10: 23-31.

Harper, J. L. 1977. Population Biology of Plants. - Academic Press, New York. pp. 237-276. ISBN 0-12-325852-9.

Henson, J. F. \& Jordan, L. S. 1982. Wild oat (Avena fatua) competition with wheat (Triticum aestivum and T. turgidum durum) for nitrate. - Weed Sci. 30: 297-300.

Kossuth, S. V. \& Biggs, R. H. 1981. Ultraviolet-B radiation effects on early seedling growth of Pinaceae species. - Can. J. For. Res. 11: 243-248.

Lee, T. D. \& Bazzaz, F. A. 1980. Effects of defoliation and competition on growth and reproduction in the annual plant Abutilon theophrasti. - J. Ecol. 68: 813-821.

Levitt, J. 1980. Responses of Plants to Environmental Stresses. Vol. 1. - Academic Press, New York. pp. 10-18. ISBN $0-12-445501-8$.
Lipton, W. J. \& O'Grady, J. J. 1980. Solar injury of "Crenshaw" muskmelons: the influence of ultraviolet radiation and of high tissue temperatures. - Agric. Meteorol. 22: 235-247.

McWhorter, C. G. \& Patterson, D. T. 1980. Ecological factors affecting weed competition in soybeans. - In World Soybean Research Conference II: Proceedings (F. T. Corbin, ed.), pp. 371-392. Westview Press, Boulder, CO. ISBN 0-89158-158-899-X.

Mueggler, W. F. 1972. Influence of competition on the response of bluebunch wheatgrass to clipping. - J. Range Manage. 25: 88-92.

National Academy of Sciences (NAS). 1979. Protection against Depletion of Stratospheric Ozone by Chlorofluorocarbons. - Washington D.C. pp. 41-57. ISBN 0-309-02947-3

- 1982. Causes and Effects of Stratospheric Ozone Reduction: An Update. - Washington D.C. pp. 145-158. ISBN 0-309-03248-2.

Pickett, S. T. A. 1980. Non-equilibrium coexistence of plants. - Bull. Torrey Bot. Club. 107: 238-248.

Sisson, W. B. \& Caldwell, M. M. 1975. Lamp/filter systems for simulation of solar UV irradiance under reduced atmospheric ozone. - Photochem. Photobiol. 21: 453-456.

- \& Caldwell, M. M. 1977. Atmospheric ozone depletion: reduction of photosynthesis and growth of a higher plant exposed to enhanced UV-B radiation. - J. Exp. Bot. 28: 691-705.

Wiens, J. A. 1977. On competition and variable environments. - Am. Sci. 65: 590-597. 